\title{
ChemComm
}

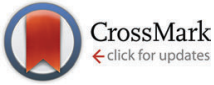

Cite this: Chem. Commun., 2015, 51, 10754

Received 14th April 2015, Accepted 22nd May 2015

DOI: $10.1039 / c 5 c c 03096 j$

www.rsc.org/chemcomm

\section{An electron-conducting pyrene-fused phenazinothiadiazole $\dagger$}

\author{
A. Belen Marco, ${ }^{a}$ Diego Cortizo-Lacalle, ${ }^{a}$ Cristian Gozalvez, ${ }^{a}$ Mikel Olano, ${ }^{a}$ \\ Ainhoa Atxabal, ${ }^{b}$ Xiangnan Sun, ${ }^{\star b}$ Manuel Melle-Franco, ${ }^{c}$ Luis E. Hueso ${ }^{\text {bd }}$ and \\ Aurelio Mateo-Alonso*ad
}

\begin{abstract}
A pyrene-fused phenazinothiadiazole that shows electron mobilities $\left(\mu_{\mathrm{e}}=0.016 \mathrm{~cm}^{2} \mathrm{~V}^{-1} \mathrm{~s}^{-1}\right)$ two orders of magnitude higher than those reported for pyrene-fused pyrazaacenes is described.
\end{abstract}

Advances in organic electronics are expected to arise by gaining control over the electronic properties of molecular materials and their organisation in thin films. ${ }^{1}$ For instance, charge transport on molecular materials depends both on the molecular structure that provides distinct electronic properties, and also on the nature of the interactions between adjacent molecules that give rise to different structures and morphologies at the nanoscale. In these terms, pyrene-fused pyrazaacenes ${ }^{2}$ (PPAs) have recently re-emerged as a platform for developing novel organic semiconductors because of their tunable electronic structure, ${ }^{3}$ enhanced stability, ${ }^{4}$ and ability to self-organise into discotic phases $^{5}$ and complex nanostructures. ${ }^{6}$ Furthermore, PPAs combines p-type pyrene and n-type azaacene residues in their structure, and therefore they can transport holes or electrons depending on their electronic structure. While hole mobilities ${ }^{7}$ up to $10^{-2} \mathrm{~cm}^{2} \mathrm{~V}^{-1} \mathrm{~s}^{-1}$ have been reported for PPA, the conduction of electrons still remains a significant challenge. In fact, mobilities in the range of $10^{-4} \mathrm{~cm}^{2} \mathrm{~V}^{-1} \mathrm{~s}^{-1}$ have been reported for electrons. ${ }^{8}$

In this work, we describe the synthesis and characterisation of pyrene-fused phenazinothiadiazole 1 (Scheme 1) that shows electron mobilities $\left(\mu_{\mathrm{e}}=0.016 \mathrm{~cm}^{2} \mathrm{~V}^{-1} \mathrm{~s}^{-1}\right)$ two orders of magnitude higher than those reported for PPA. Such enhanced electron mobilities are consistent with an optimal LUMO level alignment, a favourable molecular packing and the large aspect

\footnotetext{
${ }^{a}$ POLYMAT, University of the Basque Country UPV/EHU, Avenida de Tolosa 72, E-20018 Donostia-San Sebastian, Spain.E-mail: amateo@polymat.eu

${ }^{b}$ CIC nanoGUNE Consolider, Avenida de Tolosa 76, E-20018 Donostia-San Sebastian, Spain. E-mail: x.sun@nanogune.eu

${ }^{c}$ Centro ALGORITMI, 4710-057 Braga, Portugal

${ }^{d}$ Ikerbasque, Basque Foundation for Science, Bilbao, Spain

$\dagger$ Electronic supplementary information (ESI) available: Full synthesis, characterisation and modelling details of 1. CCDC 1056278. For ESI and crystallographic data in CIF or other electronic format see DOI: 10.1039/c5cc03096j
}

ratio of the self-assembled nanostructures obtained upon deposition.

Pyrene-fused phenazinothiadiazole 1 was prepared following the synthetic route set out on Scheme 1 . Compound $2^{9}$ was synthesised in three steps from $o$-phenylenediamine and then transformed into 4 by Stille coupling using acetylene 3 that gave almost identical results compared to a similar procedure ${ }^{10}$ with trimetyltin acetylene. Compound $\mathbf{3}$ was prepared by lithiation of the commercially available (triisopropylsilyl)acetylene followed by nucleophilic substitution with tributyltin chloride. ${ }^{11}$ Diamine 5 was obtained upon the reduction of the nitro groups of 4 with $\mathrm{Fe}$ in acetic acid. Pyrene-fused phenazinothiadiazole 1 was obtained by cyclocondensation of 5 with pyrene diketone $6^{12}$ in acetic acid at $80{ }^{\circ} \mathrm{C}$. Compound $\mathbf{1}$ is a purple solid that is readily soluble in a wide variety of organic solvents including $\mathrm{CH}_{2} \mathrm{Cl}_{2}, \mathrm{CHCl}_{3}$, THF and $o$-dichlorobenzene (ODCB).

Single crystals of pyrene-fused phenazinothiadiazole 1 were grown to investigate the underlying molecular structure and solid-state packing. Crystals suitable for X-ray diffraction were obtained by slow evaporation from $\mathrm{CH}_{2} \mathrm{Cl}_{2}$ solutions. The crystal structure of $\mathbf{1}$ (Fig. 1) confirms the molecular structure and provides an additional insight into the electronic structure. The aromatic framework of $\mathbf{1}$ is essentially flat while the ethylene substituents are slightly out of plane. The bond lengths are consistent with the presence of Clar sextets on rings $\mathrm{A}$ and $\mathrm{B}(\sim 140 \mathrm{pm})$, and a localised double bond on ring $\mathrm{C}$ (135 pm). The bonds connecting the phenanthrene residue with the diazonaphthothiadiazole residue are longer than a standard aromatic bond (147 pm), which is consistent with a smaller electron density on D and thus with Clar rules. The diazonaphthothiadiazole residue presents approximately the expected bond lengths for pyrazine (ring E), benzene (ring F) and thiadiazol (ring G). Pyrene-fused phenazinothiadiazole 1 molecules pile-up with their aromatic moieties in an antiparallel fashion so that the aromatic rings sit snugly between the bulky TIPS groups of their two neighbours at virtually the interlayer graphite distance. There are two distances at $3.35 \AA$ and another at $3.40 \AA$ A. The existing face-to-face packing 


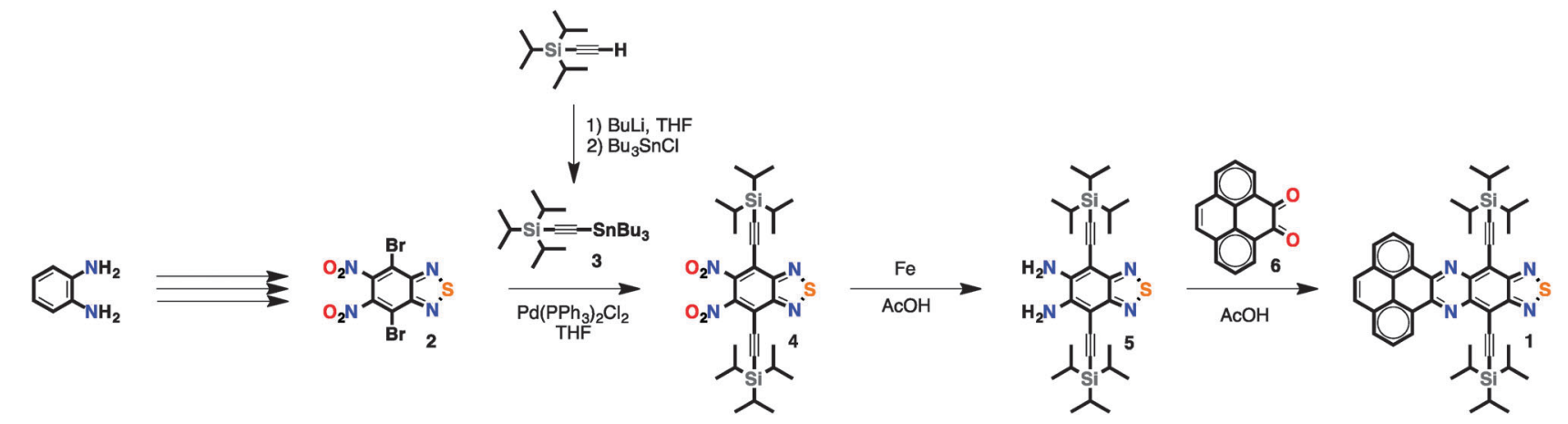

Scheme 1 Synthesis of pyrene-fused phenazinothiadiazole 1.

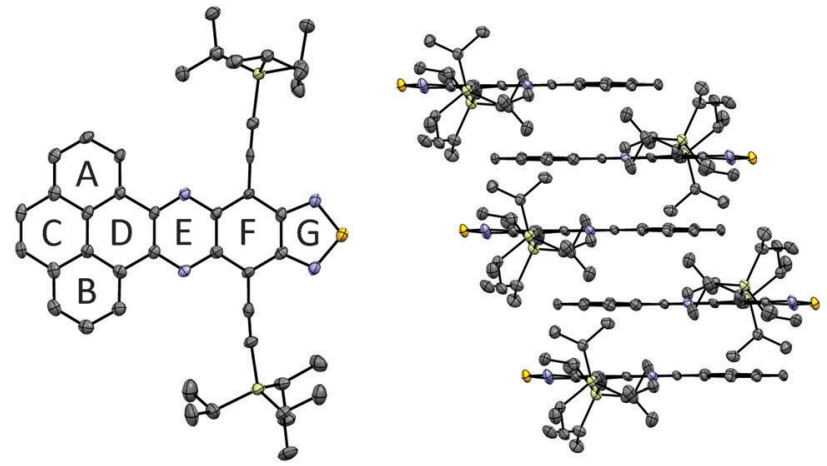

Fig. 1 X-ray structure (ellipsoids at a 50\% probability level) of pyrene-fused phenazinothiadiazole 1. C: grey, N: blue, S: orange, Si: yellow.

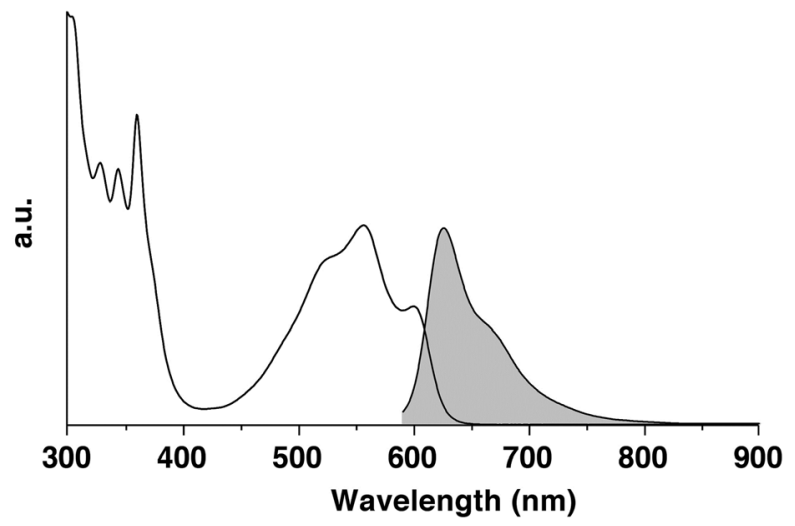

Fig. 2 Absorption (white) and photoluminescence (grey, $\lambda_{\text {exc }}=590 \mathrm{~nm}$ ) spectra of pyrene-fused phenazinothiadiazole 1.

provides a pathway for charge transport and suggests that $\mathbf{1}$ can in principle function as a semiconductor.

The absorption spectrum of 1 (Fig. 2) in ODCB displays a broad absorption band in the visible region centred at $557 \mathrm{~nm}$ $(\log \varepsilon=4.66)$ with resolved features with maxima at $525(\log \varepsilon=$ 4.66) and $599(\log \varepsilon=451) \mathrm{nm}$. Also, a well-resolved absorption band is discernible in the UV region between 300 and $375 \mathrm{~nm}$. The HOMO-LUMO gap was estimated from the absorption onset and corresponds to $1.96 \mathrm{eV}$ (Table 1). The photoluminescence spectrum of 1 in ODCB obtained by excitation at $590 \mathrm{~nm}$
Table 1 Selected optical and electrochemical parameters of 1

\begin{tabular}{cccccccc}
$\lambda_{\max }{ }^{a}$ & $\lambda_{\mathrm{em}}{ }^{a}$ & $E_{1 / 2}^{\mathrm{I}}{ }^{b}$ & $E_{1 / 2}^{\mathrm{II}}{ }^{b}$ & $E_{\text {gap }}{ }^{c}$ & $E_{\mathrm{LUMO}}{ }^{d}$ & $E_{\text {gap }}{ }^{e}$ & $E_{\mathrm{LUMO}}{ }^{e}$ \\
\hline 557 & 626 & -0.57 & -1.07 & 1.96 & -3.83 & 2.2 & -3.78
\end{tabular}

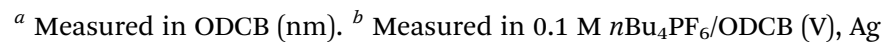
wire pseudoreference electrode referenced $v s$. SCE using ferrocene (Fc) as the internal standard $\left(E_{1 / 2}^{\mathrm{Fc}(\mathrm{SCE})}=+0.48 \mathrm{~V}\right) .{ }^{c}$ Estimated from the absorption onset (eV). ${ }^{d}$ Estimated from CV $E_{\text {ONSET }}(\mathrm{eV})$ according to $E_{\mathrm{LUMO}}=-4.8-\mathrm{e}\left(E_{\mathrm{ONSET}}-E_{1 / 2}^{\mathrm{Fc}}\right)$ where $E_{1 / 2}^{\mathrm{Fc}}$ was measured in situ. ${ }^{e}$ Calculated B3LYP-ODBC-6311g+(d2,p)/B3LYP-ODBC-631(d,p).

reveals a featureless band centred at $626 \mathrm{~nm}$ with a shoulder at $665 \mathrm{~nm}$.

To shed light on the nature of the electronic transitions in the electronic spectrum of $\mathbf{1}$, the lower energy singlet excited states were calculated using the program Gaussian $09^{13}$ and using timedependent density functional theory (TD-DFT B3LYP-ODBC6311g+(d2,p)/B3LYP-ODBC-631(d,p)). The TD-DFT model (Table S4 and Fig. S11, ESI $\dagger$ ) computes the experimental band centred at $557 \mathrm{~nm}$ as the sum of two electronic transitions: a HOMO-1 $\rightarrow$ LUMO transition at $613 \mathrm{~nm}$ and a weaker HOMO $\rightarrow$ LUMO transition at $683 \mathrm{~nm}$ with oscillator strengths of 0.30 and 0.23 respectively. In addition, the HOMO-2 $\rightarrow$ LUMO transition at $493 \mathrm{~nm}$ is allowed yet does not contribute notably for the simulated spectrum as it possesses a low oscillator strength: 0.02 .

Cyclic voltammograms of $\mathbf{1}\left(0.1 \mathrm{M} n \mathrm{Bu}_{4} \mathrm{PF}_{6}\right.$ in ODCB) exhibit two fully-reversible reduction waves at $E_{1 / 2}=-0.57$ and $-1.07 \mathrm{~V}$ (Fig. 3), which were assigned to the radical-anion and the dianion in analogy to phenazine derivatives. ${ }^{14}$ On the oxidative scan, no redox processes were observed within the solventsupported electrolyte window. The electrochemical LUMO (or electron affinity) of $\mathbf{1}(-3.83 \mathrm{eV})$ was estimated from the potential onsets of the first reduction waves (Table 1).

The theoretical estimation (B3LYP-ODBC-6311g+(d2,p)/ B3LYP-ODBC-631 $(\mathrm{d}, \mathrm{p}))$ of the HOMO-LUMO gap (2.2 eV) and the LUMO $(-3.78 \mathrm{eV})$ in vacuum is in good agreement with the HOMO-LUMO gap and the LUMO estimated from absorption spectroscopy and cyclic voltammetry, respectively (Table 1). Both HOMO and LUMO are delocalised along the diazonaphthothiadiazole residue, while the HOMO-1 is mostly located over the pyrene residue, which is consistent with recent reports ${ }^{15}$ (Fig. 4). 


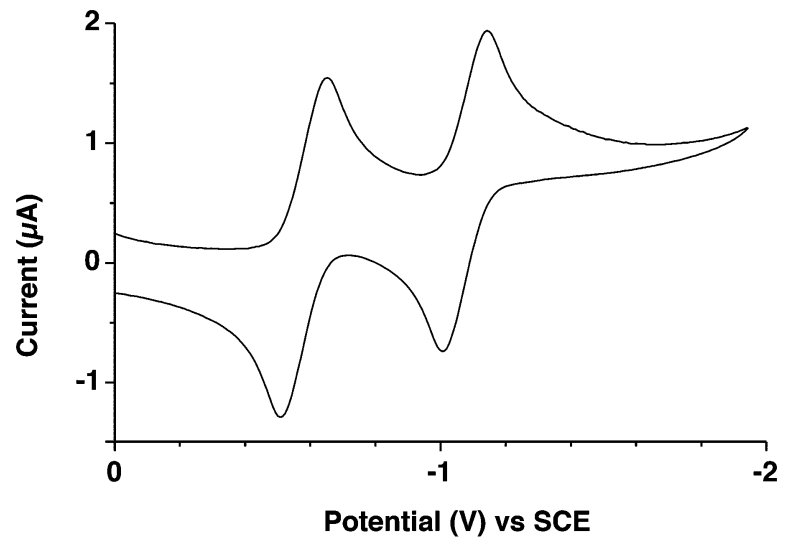

Fig. 3 Cyclic voltammograms of pyrene-fused phenazinothiadiazole 1.

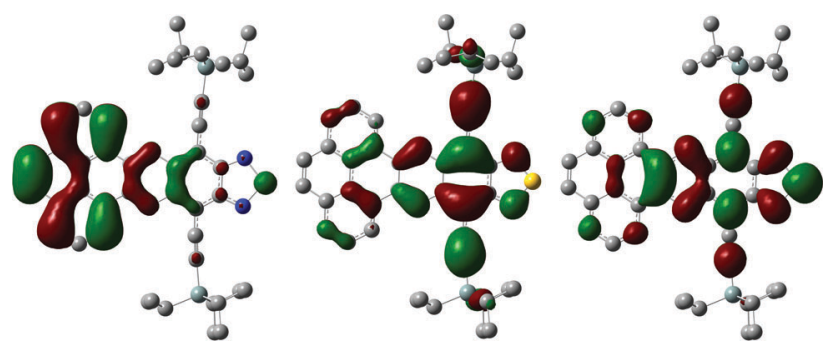

Fig. 4 HOMO-1 (left), HOMO (center) and LUMO (right) orbitals of phenazinothiadiazole 1. C: grey, Si: cyan, H: white, N: blue, S: yellow.

Thermogravimetric analysis evidences the high thermal stability of $\mathbf{1}$. No signs of decomposition were observed until $340{ }^{\circ} \mathrm{C}$ under nitrogen (Fig. S7, ESI $\dagger$ ). In addition differential scanning calorimetry under nitrogen of 1 shows a phase transition at $121^{\circ} \mathrm{C}$ that is reversible upon cooling at $117^{\circ} \mathrm{C}$ (Fig. S8, ESI $\dagger$ ).

The semiconducting properties of $\mathbf{1}$ were investigated on thin films. Bottom-contact bottom-gate transistors were fabricated on $\mathrm{Si} / \mathrm{SiO}_{2}$ substrates on top of which gold source and drain electrodes were evaporated. Then, the $\mathrm{SiO}_{2}$ surface was treated with a layer of octadecyltrichlorosilane (OTS). Finally, 1 was vacuum-deposited at different substrate temperatures $\left(25{ }^{\circ} \mathrm{C}, 80{ }^{\circ} \mathrm{C}\right.$ and $\left.120{ }^{\circ} \mathrm{C}\right)$. All the devices were characterised under vacuum after $1 \mathrm{~h}$ annealing at $120{ }^{\circ} \mathrm{C}$ (Table S2, ESI $\dagger$ ). The films of $\mathbf{1}$ show a typical behaviour for $\mathrm{n}$-type semiconductors (representative transfer and output curves are given in Fig. 5 and Fig. S10, ESI $\dagger$ respectively) with electron mobilities up to $\mu_{\mathrm{e}}=0.016 \mathrm{~cm}^{2} \mathrm{~V}^{-1} \mathrm{~s}^{-1}$ for the best performing transistor. Increasing average electron mobilities were obtained with increasing substrate temperatures during deposition $\left(\mu_{\mathrm{e}}^{25^{\circ} \mathrm{C}}=\right.$ $5.84 \times 10^{-3}<\mu_{\mathrm{e}}^{80^{\circ} \mathrm{C}}=9.34 \times 10^{-3}<\mu_{\mathrm{e}}^{120^{\circ} \mathrm{C}}=1.06 \times 10^{-2}$ ).

The different electron mobilities can be justified in terms of the thin film morphologies obtained upon vacuum-deposition at different substrate temperatures (Fig. 6). Pyrene-fused phenazinothiadiazole 1 spontaneously forms highly homogeneous rod-like nanostructures with aspect ratios that increase in terms of length $\left(L^{25{ }^{\circ} \mathrm{C}}=\sim 400 \mathrm{~nm}, L^{80^{\circ} \mathrm{C}}=\sim 860 \mathrm{~nm}\right.$ and $\left.L^{120^{\circ} \mathrm{C}}=\sim 1720 \mathrm{~nm}\right)$ and diameter $\left(\varnothing^{25^{\circ} \mathrm{C}}=\sim 110 \mathrm{~nm}\right.$, $\left.\varnothing^{80^{\circ} \mathrm{C}}=\sim 110 \mathrm{~nm}, \varnothing^{120^{\circ} \mathrm{C}}=\sim 290 \mathrm{~nm}\right)$ with increasing
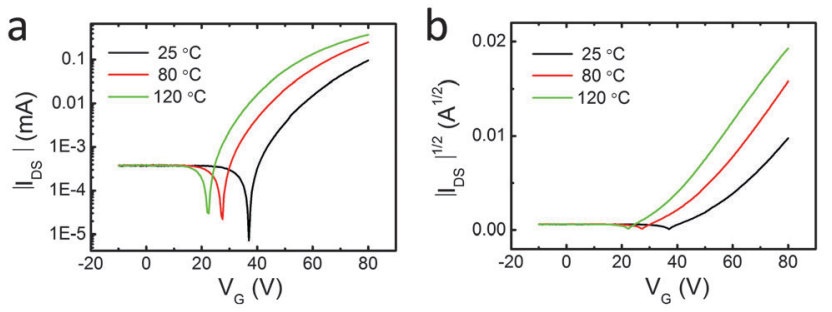

Fig. 5 (a) Transfer curves and (b) square root of the absolute values of current as a function of gate potential for pyrene-fused phenazinothiadiazole 1 thin films deposited at different substrate temperatures.
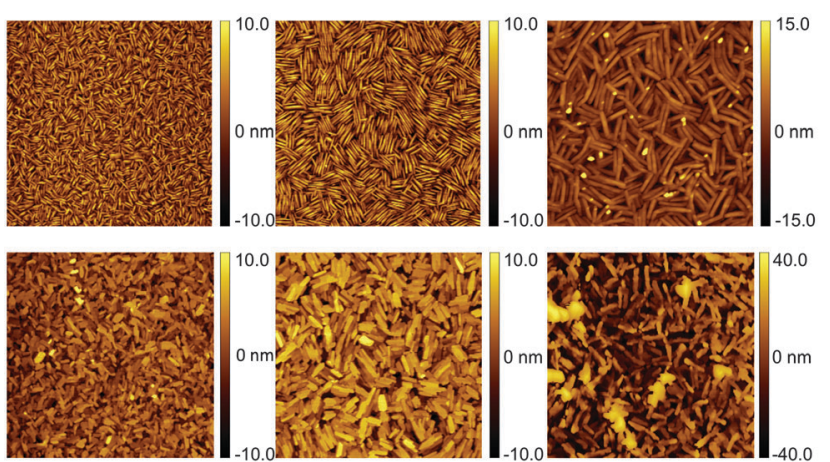

Fig. 6 Representative thin film morphologies $(5 \mu \mathrm{m} \times 5 \mu \mathrm{m})$ of phenazinothiadiazole 1 thin films deposited at $25^{\circ} \mathrm{C}$ (left), $80{ }^{\circ} \mathrm{C}$ (centre) and $120^{\circ} \mathrm{C}$ (right) before (top) and after (bottom) annealing.

substrate temperatures. After annealing at $120{ }^{\circ} \mathrm{C}$, flake-like objects that maintain approximately the lengths of the preceding rod-like nanostructures were observed. Therefore, the larger the electron mobilities the larger is the aspect ratio of the flake-like nanostructures.

We have described the synthesis of pyrene-fused phenazinothiadiazole 1 that exhibits a low LUMO level $(-3.83 \mathrm{eV})$ and packs in slipped face-to-face 1D stacks. Thin films of 1 grown by vacuum deposition show electron mobilities $\left(\mu_{\mathrm{e}}=0.016 \mathrm{~cm}^{2} \mathrm{~V}^{-1} \mathrm{~s}^{-1}\right)$ remarkably higher than those previously reported for PPA. Increasing electron mobilities were obtained with increasing substrate temperatures during deposition, which can be rationalised in terms of the larger aspect ratio of the self-assembled nanostructures obtained at higher temperatures. Overall this work demonstrates the potential of PPA to develop electron deficient materials for field-effect transistors that allow control of their properties not only at the molecular level but also at the supramolecular level.

We are grateful to the Basque Science Foundation for Science (Ikerbasque), POLYMAT, University of the Basque Country (SGIker), Deutsche Forschungsgemeinschaft (AU 373/ 3-1 and MA 5215/4-1), Gobierno de España (Ministerio de Economía y Competitividad, MAT2012-35826 and MAT201237638), Gobierno Vasco (BERC program), Diputación Foral de Guipuzcoa, the Fundação para a Ciência e a Tecnologia, ON2 (NORTE-07-0162-FEDER-000086) and the European Union (ERA-Chemistry, Career Integration Grant No. 618247, ERC Starting Grant 257654-SPINTROS and FEDER). 


\section{Notes and references}

1 (a) M. Bendikov, F. Wudl and D. F. Perepichka, Chem. Rev., 2004, 104, 4891-4946; (b) J. E. Anthony, Chem. Rev., 2006, 106, 5028-5048; (c) V. Coropceanu, J. Cornil, D. A. da Silva Filho, Y. Olivier, R. Silbey and J.-L. Brédas, Chem. Rev., 2007, 107, 926-952; (d) H. E. Katz, A. J. Lovinger, J. Johnson, C. Kloc, T. Siegrist, W. Li, Y. Y. Lin and A. Dodabalapur, Nature, 2000, 404, 478-481; (e) H. Li, F. S. Kim, G. Ren, E. C. Hollenbeck, S. Subramaniyan and S. A. Jenekhe, Angew. Chem., Int. Ed., 2013, 52, 5513-5517.

2 A. Mateo-Alonso, Chem. Soc. Rev., 2014, 43, 6311-6324.

3 (a) A. Mateo-Alonso, C. Ehli, K. H. Chen, D. M. Guldi and M. Prato, J. Phys. Chem. A, 2007, 111, 12669-12673; (b) A. Mateo-Alonso, N. Kulisic, G. Valenti, M. Marcaccio, F. Paolucci and M. Prato, Chem. - Asian J., 2010, 5, 482-485; (c) N. Kulisic, S. More and A. Mateo-Alonso, Chem. Commun., 2011, 47, 514-516; (d) S. More, R. Bhosale, S. Choudhary and A. Mateo-Alonso, Org. Lett., 2012, 14, 4170-4173; (e) R. García, S. More, M. Melle-Franco and A. MateoAlonso, Org. Lett., 2014, 16, 6096-6099; $(f)$ S. More, R. Bhosale and A. Mateo-Alonso, Chem. - Eur. J., 2014, 20, 10626-10631; (g) S. More, S. Choudhary, A. Higelin, I. Krossing, M. Melle-Franco and A. MateoAlonso, Chem. Commun., 2014, 50, 1976-1979.

4 (a) J. K. Stille and E. L. Mainen, J. Polym. Sci., Part B: Polym. Lett., 1966, 4, 665-667; (b) J. K. Stille and E. L. Mainen, Macromolecules, 1968, 1, 36-42; (c) K. Imai, M. Kuhihara, L. Mathias, J. Wittmann, W. B. Alston and J. K. Stille, Macromolecules, 1973, 6, 158-162.

5 (a) S. Leng, L. H. Chan, J. Jing, J. Hu, R. M. Moustafa, R. M. V. Horn, M. J. Graham, B. Sun, M. Zhu, K.-U. Jeong, B. R. Kaafarani, W. Zhang, F. W. Harris and S. Z. D. Cheng, Soft Matter, 2010, 6, 100-112; (b) J. Hu, D. Zhang, S. Jin, S. Z. D. Cheng and F. W. Harris, Chem. Mater., 2004, 16, 4912-4915.

6 (a) M. Grzelczak, N. Kulisic, M. Prato and A. Mateo-Alonso, Chem. Commun., 2010, 46, 9122-9124; (b) K. K. McGrath, K. Jang, K. A. Robins and D.-C. Lee, Chem. - Eur. J., 2009, 15, 4070-4077; (c) K. Jang, J. M. Kinyanjui, D. W. Hatchett and D.-C. Lee, Chem. Mater., 2009, 21, 2070-2076; (d) D. C. Lee, K. K. McGrath and K. Jang, Chem. Commun., 2008, 3636-3638; (e) D. C. Lee, K. Jang, K. K. McGrath, R. Uy, K. A. Robins and D. W. Hatchett, Chem. Mater., 2008, 20, 3688-3695.
7 (a) B. R. Kaafarani, L. A. Lucas, B. Wex and G. E. Jabbour, Tetrahedron Lett., 2007, 48, 5995-5998; (b) J. Guo, Y. Xu, S. Jin, L. Chen, T. Kaji, Y. Honsho, M. A. Addicoat, J. Kim, A. Saeki, H. Ihee, S. Seki, S. Irle, M. Hiramoto, J. Gao and D. Jiang, Nat. Commun., 2013, 4, 2736.

8 J. Shao, J. Chang and C. Chi, Org. Biomol. Chem., 2012, 10, 7045-7052.

9 E. Wang, L. Hou, Z. Wang, S. Hellström, W. Mammo, F. Zhang, O. Inganäs and M. R. Andersson, Org. Lett., 2010, 12, 4470-4473.

10 C. An, S. Zhou and M. Baumgarten, Cryst. Growth Des., 2015, 15, 1934-1938.

11 R. C. DeCicco, A. Black, L. Li and N. S. Goroff, Eur. J. Org. Chem., 2012, 4699-4704.

12 J. Hu, D. Zhang and F. W. Harris, J. Org. Chem., 2005, 70, 707-708. 13 M. J. Frisch, G. W. Trucks, H. B. Schlegel, G. E. Scuseria, M. A. Robb, J. R. Cheeseman, G. Scalmani, V. Barone, B. Mennucci, G. A. Petersson, H. Nakatsuji, M. Caricato, X. Li, H. P. Hratchian, A. F. Izmaylov, J. Bloino, G. Zheng, J. L. Sonnenberg, M. Hada, M. Ehara, K. Toyota, R. Fukuda, J. Hasegawa, M. Ishida, T. Nakajima, Y. Honda, O. Kitao, H. Nakai, T. Vreven, J. A. Montgomery Jr, J. E. Peralta, F. Ogliaro, M. J. Bearpark, J. Heyd, E. N. Brothers, K. N. Kudin, V. N. Staroverov, R. Kobayashi, J. Normand, K. Raghavachari, A. P. Rendell, J. C. Burant, S. S. Iyengar, J. Tomasi, M. Cossi, N. Rega, N. J. Millam, M. Klene, J. E. Knox, J. B. Cross, V. Bakken, C. Adamo, J. Jaramillo, R. Gomperts, R. E. Stratmann, O. Yazyev, A. J. Austin, R. Cammi, C. Pomelli, J. W. Ochterski, R. L. Martin, K. Morokuma, V. G. Zakrzewski, G. A. Voth, P. Salvador, J. J. Dannenberg, S. Dapprich, A. D. Daniels, Ö. Farkas, J. B. Foresman, J. V. Ortiz, J. Cioslowski and D. J. Fox, Gaussian, Inc., Wallingford, CT, USA, 2009.

14 (a) A. M. Alonso, R. Horcajada, H. J. Groombridge, R. Mandalia, M. Motevalli, J. H. P. Utley and P. B. Wyatt, Chem. Commun., 2004, 412-413; (b) A. M. Alonso, R. Horcajada, H. J. Groombridge, R. Chudasama, M. Motevalli, J. H. P. Utley and P. B. Wyatt, Org. Biomol. Chem., 2005, 3, 2832-2841; (c) A. M. Alonso, R. Horcajada, M. Motevalli, J. H. P. Utley and P. B. Wyatt, Org. Biomol. Chem., 2005, 3, 2842-2847.

15 R. Garcia, M. Melle-Franco and A. Mateo-Alonso, Chem. Commun., 2015, 51, 8037-8040. 